\title{
Update in the prenatal management of sacrococcygeal teratomas and the outcome of the newborn - case report
}

\author{
Bianca-Margareta Mihai', Roxana-Elena Bohiltea ${ }^{1,2}$, Vlad Dima ${ }^{3}$, Alina Veduta', \\ Teodor Salmen ${ }^{4,5}$, Tiberiu Augustin Georgescu ${ }^{6,7}$, Maria Irina Vladareanu ${ }^{8}$, \\ Valentin-Nicolae Varlas ${ }^{1,2}$ \\ ${ }^{1}$ Department of Obstetrics and Gynecology, Filantropia Clinical Hospital, Bucharest, Romania \\ 2Department of Obstetrics and Gynecology, "Carol Davila" University of Medicine and Pharmacy, \\ Bucharest, Romania \\ ${ }^{3}$ Department of Neonatology, Filantropia Clinical Hospital, Bucharest, Romania \\ "Doctoral School, "Carol Davila" University of Medicine and Pharmacy, Bucharest, Romania \\ 5"N.C. Paulescu“ National Institute of Diabetes, Nutrition and Metabolic Disorders, Bucharest, Romania \\ ${ }^{6}$ Department of Pathology, "Carol Davila" University of Medicine and Pharmacy, Bucharest, Romania \\ ${ }^{7}$ National Institute for Mother and Child Health "Alessandrescu-Rusescu", Bucharest, Romania \\ ${ }^{8}$ Faculty of Medicine, "Carol Davila" University of Medicine and Pharmacy, Bucharest, Romania
}

\begin{abstract}
Sacrococcygeal teratomas complicate approximatively 1 in 27,000 pregnancies, being the most common congenital germ cell tumors in infants. The diagnosis is suspected using ultrasonographic examination and confirmed after a pathology report is performed. The main issue complicating fetuses with sacrococcygeal teratomas is represented by the rapid growth and the great need of blood supply captured by the tumor that interferes with the fetal growth and fetal wellbeing, generating heart failure and, unfortunately, increasing neonatal mortality. Thus, ultrasonographic monitoring is fundamental, to diagnose, closely monitor the growth and vascularization of the tumor and to ameliorate the neonatal prognosis by establishing the proper time of birth. There are specialized healthcare centers that could perform in utero surgery with the aim to aid the normal growth and development of the fetus until term, when a curative surgery is performed to the newborn. In cases complicated with heart failure leading to fetal hydrops, pregnancy termination could be a valuable option for the mothers, as soon as the etiology and the stage of heart decompensation are known. We present a case of a fetal sacrococcygeal teratoma in a 36-year-old pregnant woman, an uninvestigated pregnancy that had a dreadful outcome with neonatal death.
\end{abstract}

Keywords: sacrococcygeal teratoma, fetal cardiac heart failure, Doppler ultrasound, neonatal death

\section{INTRODUCTION}

Sacrococcygeal teratomas (SCTs) are the most frequent congenital germ cell tumors met in infants and young children. SCTs represent $40 \%$ of germ cell tumors, respectively $70 \%$ of all extragonadal germ cell tumors among the pediatric population $(1,2)$. SCT represents the most frequent prenatal diagnosis of fetal neoplasm; its incidence is estimated to 1 in 27,000 births (3) and has a higher prevalence in females than in male fetuses, with a ratio of 3 to
4:1 (4). Their origin is in the totipotent cells of Hensen's node and SCTs usually contain tissues that derive from multiple germ layers (5). Teratomas usually present cystic, solid or mixed elements. SCTs are not limited by a pseudocapsule or capsule, thus complete resection being hardly accomplished (4). The histopathologic form can present as welldifferentiated mature teratomas or even as immature or malignant teratomas. The malignant postnatal SCTs percentage varies between 11 and 35\%; the 
most frequent component of malignity is represented by a yolk sac factor producing alpha-fetoprotein $(4,6,7)$. There have not been described any associations between genetic changes and immature and mature teratomas (8).

The clinical aspects of SCTs vary from a barely symptomatic child: pain, paralysis or weakness, to a caudal mass of the fetus or a tumor in infancy that could be associated with obstruction of the urinary bladder or rectum (9). In order to stratify SCTs, the Altman Classifications was developed, with 4 types of tumors: type I with predominant external tumor, type II external tumor but with intrapelvic extension, type III with apparent external tumor, but the mass was predominant in the abdomen and type IV tumor completely with presacral tumor (10).

Nowadays, ultrasonography used in prenatal screening moved the SCTs diagnosis in utero, the majority in the second trimester as type I or II Altman $(11,12)$. They appear as near the distal spine solid or mixed masses, sometimes in association with structural anomalies such as hydronephrosis or rectal stenosis or atresia, and even cardiomegaly secondary to vascular shunting $(11,12)$.

Another important tool for the characterization of the intrapelvic or abdominal tumor extent or compression is represented by fetal magnetic resonance imaging (MRI), that can be helpful in prenatal counseling and preoperative planning for surgical resection, but this is not easily available (13).

\section{CASE PRESENTATION}

A 36-year-old pregnant patient with decreased educational level and an unmonitored 25 weeks pregnancy presents to the obstetrics emergency room for uterine contractions. From the obstetrical history we noted a previous pregnancy with apparently no complications and an abortion. During the ultrasound examination a massive sacrococcygeal teratoma type III Altman was suspected along with established heart failure and lower urinary obstruction with terminal kidney failure. The ultrasonographic elements that pleaded in favor of an ultrasonographic diagnosis of sacrococcygeal teratoma were the presence of a large tumor (Figure 1), a decrease in the amniotic fluid index, a dilated urinary bladder (Figure 2), cardiomegaly (Figure 3), fetal oedema, ascites and pericardial effusion and very high systolic velocity in the middle cerebral artery (Figure 4).

The patient delivers spontaneously a newborn that, unfortunately, due to the heart failure did not survive. A pathologic examination was performed that revealed intraabdominal tumor (Figure 5) and sacrococcygeal tumor excrescence, dilated urinary bladder with absent bladder-urethral orifice, abnor- mal kidneys, pulmonary hypoplasia and pathological facies, confirming the ultrasonographic diagnosis of a SCT in a fetus with multiple malformations.

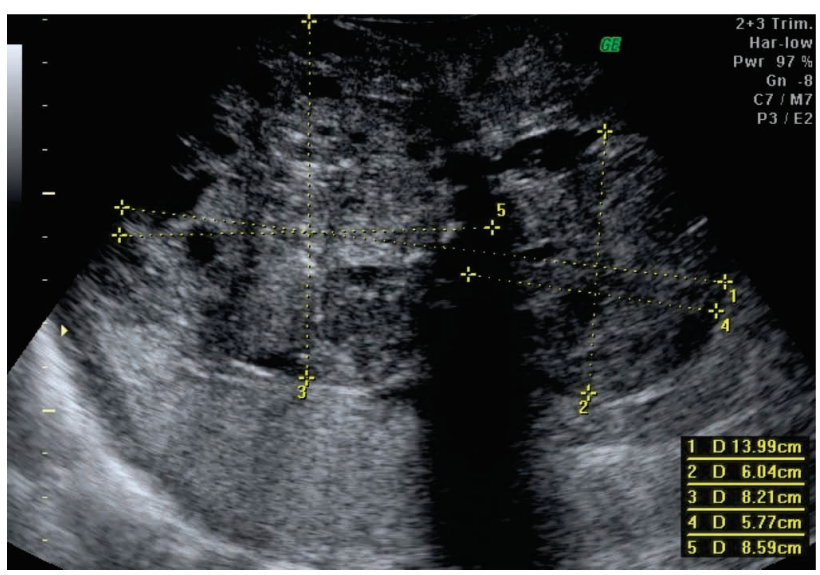

FIGURE 1. Ultrasonographic teratoma measurements in 2 planes with ischemia gaps

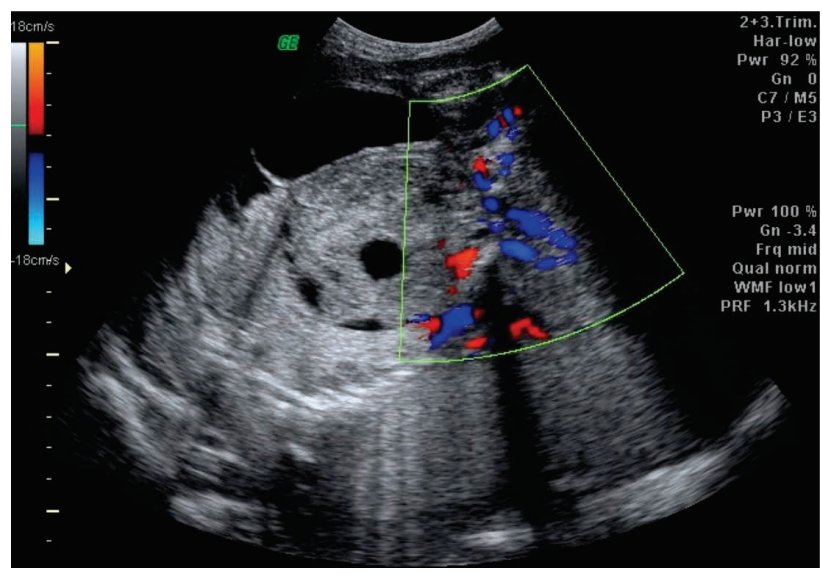

FIGURE 2. 2D ultrasonographic examination with color Doppler: sacrococcygeal teratoma located in the abdomen presenting a central necrosis area, anterior dilated urinary bladder and pedicle area with Doppler signal suggestive of wide vascular anchoring

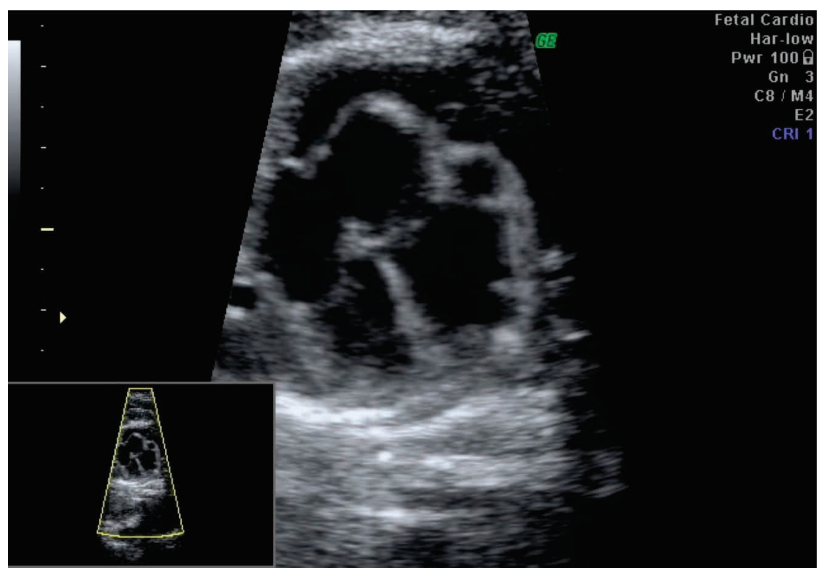

FIGURE 3. Ultrasonographic image of 4-chamber heart, cardiomegaly and pericardial effusion, dilated coronary sinus 


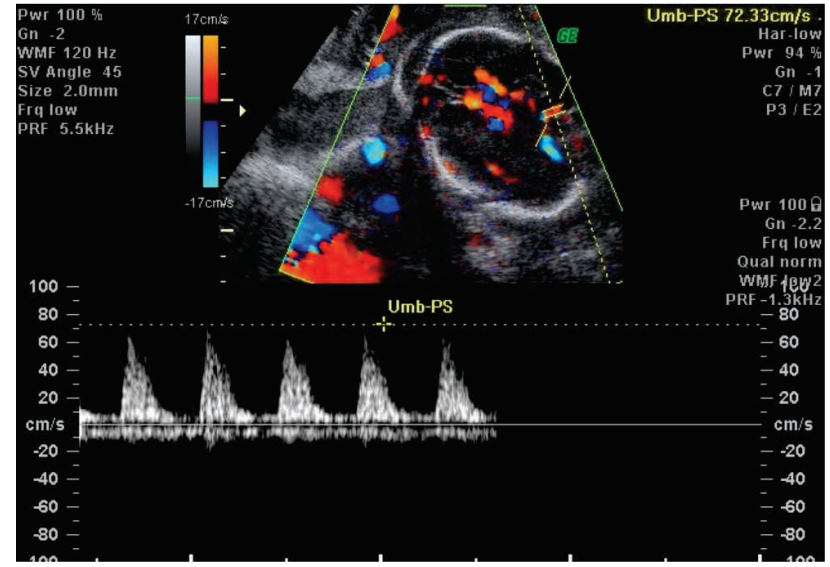

FIGURE 4. Increased speed on the Doppler evaluation of the middle cerebral artery within the heart failure status assessment

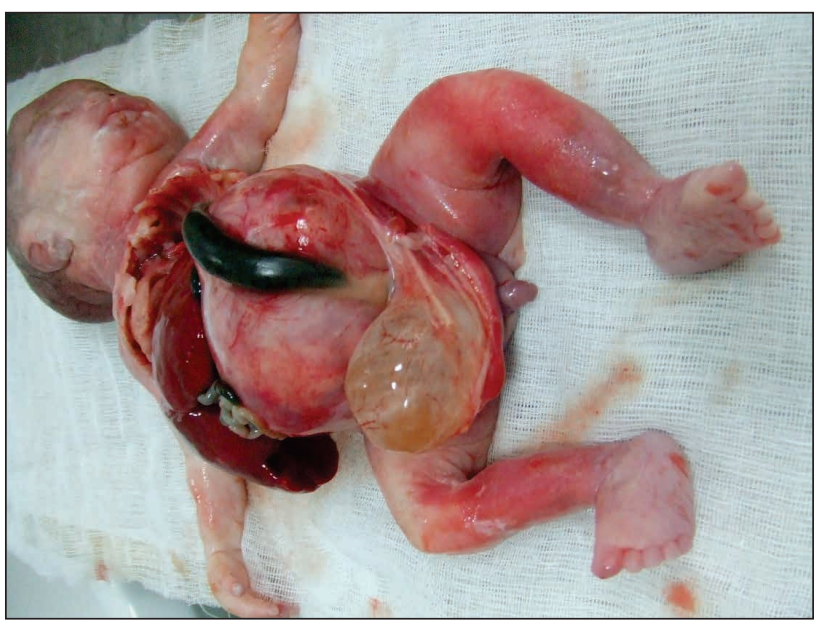

FIGURE 5. Fetal autopsy image: the giant teratoma that occupies the entire abdominal cavity is highlighted and the bladder excessively dilated due to the compression exerted by the teratoma on the bladder

\section{DISCUSSION}

The differential diagnosis is realized with the distal neural tube defect or myelomeningocele or myelocystocele. The neural tube defect is represented by posteriorly splayed spinal elements, while SCTs always have a portion proximal to the coccyx. On the other hand, both can present elevated maternal and amniotic levels of alpha-fetoprotein (12).

\section{Ultrasound examination}

The evaluation and monitoring are made using ultrasound examination of the placenta, fetus and tumoral mass during pregnancy, in order to predict fetal cardiac decompensation to hydrops. The frequency is dictated by tumoral dimensions, its vascularization and incidental findings. The fetal echocardiography is needed in tumors that are predominantly solid and/or intensely vascularized, in order to assess a possible high-output cardiac state and fetuses with poor prognosis (14). The sacro- coccygeal teratoma ultrasonographic evaluation includes serial monitoring of the tumor size and vascular flow of the SCT solid compound using Doppler ultrasound due to the fact that tumors presenting rapid growth and the predominant solid compound have a tendency to indulge into a vascular steal phenomenon, which introduces the fetus to an elevated risk of developing fetal hydrops $(15,16)$. A recent study by Benachi et al. (17) involving 44 fetuses concluded that large SCTs meaning $>10 \mathrm{~cm}$, specifically those presenting solid compound with an increased vascularization are associated with an increased perinatal mortality rate while cystic lesions, including large SCTs $(>10 \mathrm{~cm}$ ), which present mild to absent vascularization usually present a slow growth and a greater prognosis and neonatal outcome. The most frequent markers for fetal hydrops such as polyhydramnios and the thickening of the placenta should be evaluated; oligohydramnios occurs in cases of SCTs obstructing the bladder. The regularity of the ultrasound evaluations should be established taking into account each case's particularities. For elevated risk tumors the evaluations could be as frequent as twice a week; for low risk respectively small, cystic or with a diminished vascularity SCTs, the frequency can be reduced to every two weeks. The cardiac balance should be performed in fetuses presenting SCTs with a considerable solid compound or vascularization. A poor prognosis can be detected using a fetal cardiac profile assessment including combined vascular output, cardiac dimension $\mathrm{z}$ scores, cardiothoracic ratio and valvular regurgitation (18).

\section{Surgical and postoperative management}

During pregnancy, in utero interventions do not usually have a curative role but their major target is to diminish the burden of the SCT on the fetal cardiovascular system, permitting the fetal recovery, future growth and maturation in utero with the final surgical procedure taking place after birth. Certain centers have specialized in in utero open fetal surgery, being an option for elevated risk SCTs (hydrops occurred at inadequate gestational age for birth and further neonatal care) (19). Open fetal surgery should not be performed if the fetus presents a type III or IV Altman SCT, when the maternal cervix is shortened, in case of severe placentomegaly or if the mothers present other pathologies contraindicating the surgery (19). Among the minimally invasive procedures used for the management of SCTs complicated with hydrops are: radiofrequency ablation $(20,21)$, laser ablation $(22,23)$, cyst aspiration (24) and the obstructive uropathy treatment using bladder drainage $(12,25)$. In a case series published in 2014 by Van Mieghem et al. (26) the overall perinatal survival percentage was 50\%: 
the success rate for minimally invasive treatment for SCTs was $44 \%$, the surviving rates of the fetuses presenting hydrops and for the ones without, were $30 \%$ and $67 \%$, respectively. Postnatally, complete resection of the SCT is attempted, which usually implies removal of the coccyx. A second surgery could be necessary for complete removal of the tumor especially for those with malignant elements $(6,27)$. Despite complete tumor resection, the most frequent sequelae that appear post surgically are represented by bowel dysfunction including soiling and total fecal incontinence in isolated cases, as well as urinary incontinence (28). Altman type I SCTs usually do not present any urologic or anorectal complication.

Regarding postoperative follow-up, benign SCTs usually do not require postoperative therapy after complete resection $(7,29)$. For malignant SCTs, the most frequent adjuvant therapy used is platinumbased chemotherapy (6).

\section{Fetal prognosis}

The fetal prognosis is tightly correlated with the tumor's volume and vascularization $(16,30)$. The most helpful ultrasonographic measurement is the tumor-volume-to-fetal-weight ratio (TFR). A TFR value greater than 0.12 before 24 weeks of gestation has been associated with an obscure prognosis in several studies (16,31-33). The reported risk of hydrops, need for fetal intervention and perinatal death is 4.7 times higher in cases with TFR $>0.12$ and 6.2 times higher before 32 gestational weeks in cases with TFR $\geq 0.11$ (32). Perinatal mortality of SCTs ranges between 25 to $50 \%$ including intrauterine death, pregnancy termination and neonatal death (12). The perinatal possible scenario includes complications such as spontaneous hemorrhage of the SCT, preterm labor or maternal Mirror syndrome or Ballantynes syndrome characterized by maternal generalized edema with commonly pulmonary affection which 'mirrors' the edema of fetus suffering from hydrops and increased the placenta thickness (34).

A case series of 17 pregnancies published in 2020 by Özsürmeli et al. (35) included one ongoing pregnancy and 16 finalized pregnancies with SCT. Among the 16 finalized pregnancies, in 5 cases con-

\section{REFERENCES}

1. Audet IM, Goldhahn RT Jr, Dent TL. Adult sacrococcygeal teratomas. Am Surg. 2000;66(1):61.

2. Ng EW, Porcu P, Loehrer PJ Sr. Sacrococcygeal teratoma in adults: case reports and a review of the literature. Cancer. 1999;86(7):1198.

3. Swamy R, Embleton N, Hale J. Sacrococcygeal teratoma over two decades: birth prevalence, prenatal diagnosis and clinical outcomes. Prenat Diagn. 2008;28(11):1048. sisting of 3 cases of SCTs associating early-onset heart failure and 2 cases of SCTs associating central nervous defects, the therapeutical management was medical termination of the pregnancy; remarkably is a case of a 26 gestational weeks pregnancy with a fetus with a type III Altman SCT associating Dandy-Walker malformation, agenesis of corpus callosum, multicystic dysplastic kidney and a normal karyotype analysis; two of the seventeen cases of SCTs, the first type I Altman and the second type III Altman, had associated polyhydramnios and premature preterm rupture of membranes, the fetuses being delivered by cesarean section at 28 respectively 29 gestational weeks, but unfortunately dying in the neonatal period. Among the 9 survivors of the SCT 5 underwent surgery; 4 of the nine survivors presented type I Altman SCT, there were 3 cases of type II Altman SCT and 2 cases of type III Altman SCT.

Regarding our case, the particularity is the expanded volume of the tumor in comparison with the gestational age respectively the fetal weight. We can confirm the well-known literature fact that SCTs with solid component with increased vascularization have a worse prognosis due to the risk of heart failure which occurred in the presented case. Maybe the pregnancy could have had a better outcome or the mother could have had the option of an earlier termination of the pregnancy after counseling regarding the fetal and neonatal risks, if the SCT should be properly diagnosed during a prenatal screening evaluation for fetal anomalies that have never been requested by the mother. The presence of heart failure with cardiomegaly, ascites, oedema and pleural effusion are signs that indicate a longlasting negative evolution of the SCT.

\section{CONCLUSIONS}

In conclusion, sacrococcygeal teratomas represent fetal tumors that require early diagnosis preferably by ultrasonographic examination and, moreover, individualized ultrasonographic monitoring in order to establish the management of the case, taking into consideration the tumor size, the tumor morphology, the growth rapidity, and the characteristics of the vascularization.

Conflict of interest: none declared Financial support: none declared

4. Rescorla FJ, Sawin RS, Coran AG, Dillon PW, Azizkhan RG. Long-term outcome for infants and children with sacrococcygeal teratoma: a report from the Childrens Cancer Group. J Pediatr Surg. 1998; 33(2):171.

5. Srivastava A, Jaiswal AK, Jain K, et al. Sacrococcygeal teratoma. J Pediatr Neurosci 2010;5:30-31.

6. Calaminus G, Schneider DT, Bökkerink JP, Gadner H, Harms D, Willers R, Göbel U. Prognostic value of tumor size, metastases, extension into 
bone, and increased tumor marker in children with malignant sacrococcygeal germ cell tumors: a prospective evaluation of 71 patients treated in the German cooperative protocols Maligne Keimzelltumoren (MAKEI) 83/86 and MAKEI 89. J Clin Oncol. 2003; 21(5):781.

7. Marina NM, Cushing B, Giller R, et al. Complete surgical excision is effective treatment for children with immature teratomas with or without malignant elements: A Pediatric Oncology Group/Children's Cancer Group Intergroup Study. J Clin Oncol. 1999;17(7):2137.

8. Harms D, Zahn S, Göbel U, Schneider DT. Pathology and molecular biology of teratomas in childhood and adolescence. Klin Padiatr. 2006; 218(6):296.

9. Mahour GH. Sacrococcygeal teratomas. CA Cancer J Clin. 1988; 38(6):362-7.

10. Altman P, Randolph J, Lilly J. Sacrococcygeal teratoma: American Academy of Pediatrics Surgical Section survey - 1973. J. Pediatr. Surg. 1974;9(3):389-398.

11. Ayed A, Tonks AM, Lander A, Kilby MD. A review of pregnancies complicated by congenital sacrococcygeal teratoma in the West Midlands region over an 18-year period: population-based, cohort study. Prenat Diagn. 2015;35(11):1037-47.

12. Wilson RD, Hedrick H, Flake AW, et al. Sacrococcygeal teratomas: prenatal surveillance, growth and pregnancy outcome. Fetal Diagn Ther. 2009;25(1):15-20.

13. Danzer E, Hubbard AM, Hedrick HL, et al. Diagnosis and characterization of fetal sacrococcygeal teratoma with prenatal MRI. AJR Am J Roentgenol. 2006;187(4):W350-6.

14. Adzick NS. Open fetal surgery for life-threatening fetal anomalies. Semin Fetal Neonatal Med. 2010;15(1):1-8.

15. Flake AW. Fetal sacrococcygeal teratoma. Semin Pediatr Surg. 1993;2(2):113-20.

16. Sy ED, Filly RA, Cheong ML, Clifton MS, Cortes RA, Ohashi S, et al. Prognostic role of tumor-head volume ratio in fetal sacrococcygeal teratoma. Fetal Diagn Ther. 2009;26(2):75-80.

17. Benachi A, Durin L, Vasseur Maurer S, Aubry MC, Parat S, Herlicoviez M, Nihoul-Fekete C, Dumez Y, Dommergues M. Prenatally diagnosed sacrococcygeal teratoma: a prognostic classification. J Pediatr Surg. 2006;41(9):1517-21.

18. Byrne FA, Lee H, Kipps AK, Brook MM, Moon-Grady AJ. Echocardiographic risk stratification of fetuses with sacrococcygeal teratoma and twin-reversed arterial perfusion. Fetal Diagn Ther. 2011;30(4):280-8.

19. Roybal JL, Moldenhauer JS, Khalek N, Bebbington MW, Johnson MP, Hedrick HL, Adzick NS, Flake AW. Early delivery as an alternative management strategy for selected high-risk fetal sacrococcygeal teratomas. J Pediatr Surg. 2011;46(7):1325-32.

20. Lam YH, Tang MH, Shek TW. Thermocoagulation of fetal sacrococcygeal teratoma. Prenat Diagn. 2002;22(2):99-101.

21. Paek BW, Jennings RW, Harrison MR, Filly RA, Tacy TA, Farmer DL, Albanese CT. Radiofrequency ablation of human fetal sacrococcygeal teratoma. Am J Obstet Gynecol. 2001;184(3):503-7.
22. Makin EC, Hyett J, Ade-Ajayi N, Patel S, Nicolaides K, Davenport M. Outcome of antenatally diagnosed sacrococcygeal teratomas: single-center experience (1993-2004). J Pediatr Surg. 2006; 41(2):388-93.

23. Hecher K, Hackelöer BJ. Intrauterine endoscopic laser surgery for fetal sacrococcygeal teratoma. Lancet. 1996;347(8999):470.

24. Lee MY, Won HS, Hyun MK, Lee HY, Shim JY, Lee PR, Kim A. Perinatal outcome of sacrococcygeal teratoma. Prenat Diagn. 2011; 31(13):1217-21

25. Jouannic JM, Dommergues M, Auber F, Bessis R, Nihoul-Fekete C, Dumez $Y$. Successful intrauterine shunting of a sacrococcygeal teratoma (SCT) causing fetal bladder obstruction. Prenat Diagn. 2001; 21(10):824-6.

26. Van Mieghem T, Al-Ibrahim A, Deprest J, Lewi L, Langer JC, et al. Minimally invasive therapy for fetal sacrococcygeal teratoma: case series and systematic review of the literature. Ultrasound Obstet Gynecol. 2014;43(6):611-9.

27. Marina N, London WB, Frazier AL, Lauer S, Rescorla F, et al. Prognostic factors in children with extragonadal malignant germ cell tumors: a pediatric intergroup study. J Clin Oncol. 2006;24(16):2544-8.

28. Derikx JP, De Backer A, van de Schoot L, Aronson DC, de Langen ZJ, van den Hoonaard TL, Bax NM, van der Staak F, van Heurn LW. Long-term functional sequelae of sacrococcygeal teratoma: a national study in The Netherlands. J Pediatr Surg. 2007;42(6):1122-6.

29. Derikx JP, De Backer A, van de Schoot L, Aronson DC, de Langen ZJ, van den Hoonaard TL, Bax NM, van der Staak F, van Heurn LW. Factors associated with recurrence and metastasis in sacrococcygeal teratoma. Br J Surg. 2006;93(12):1543-8.

30. Lee SM, Suh DH, Kim SY, Kim MK, Oh S, Song SH, et al. Antenatal Prediction of Neonatal Survival in Sacrococcygeal Teratoma. J Ultrasound Med. 2018;37(8):2003-2009.

31. Rodriguez MA, Cass DL, Lazar DA, Cassady Cl, et al. Tumor volume to fetal weight ratio as an early prognostic classification for fetal sacrococcygeal teratoma. J Pediatr Surg. 2011;46(6):1182-5.

32. Shue E, Bolouri M, Jelin EB, Vu L, Bratton B, et al. Tumor metrics and morphology predict poor prognosis in prenatally diagnosed sacrococcygeal teratoma: a 25-year experience at a single institution. J Pediatr Surg. 2013;48(6):1225-31.

33. Akinkuotu AC, Coleman A, Shue E, Sheikh F, Hirose S, Lim FY, Olutoye OO. Predictors of poor prognosis in prenatally diagnosed sacrococcygeal teratoma: A multiinstitutional review. J Pediatr Surg. 2015;50(5):771-4.

34. Kremer ME, Wellens LM, Derikx JP, van Baren R, Heij HA, Wijnen MH, Wijnen RM, van der Zee DC, van Heurn LW. Hemorrhage is the most common cause of neonatal mortality in patients with sacrococcygeal teratoma. J Pediatr Surg. 2016;51(11):1826-1829.

35. Özsürmeli M, Büyükkurt S, Sucu M, Arslan E, Mısırlıoğlu S, Akçabay Ç, Kayapınar M, Demir SC, Evrüke iC. Evaluation of prenatally diagnosed fetal sacrococcygeal teratomas: A case series of seventeen pregnancies from South-central Turkey. Turk J Obstet Gynecol. 2020;17(3):170-174. 